\title{
Emergency Department Visits after Diagnosed Chronic Obstructive Pulmonary Disease in Aboriginal People in Alberta, Canada
}

\author{
Maria B. Ospina, $\mathrm{PhD}^{*+}$; Brian H. Rowe, MD, MSc ${ }^{* \dagger}$; Donald Voaklander, $\mathrm{PhD}^{*}$; \\ Ambikaipakan Senthilselvan, PhD*; Michael K. Stickland, $\mathrm{PhD}^{\dagger \S}$; Malcolm King, PhD
}

\section{ABSTRACT}

Objectives: This retrospective cohort study compared rates of emergency department (ED) visits after a diagnosis of chronic obstructive pulmonary disease (COPD) in the three Aboriginal groups (Registered First Nations, Métis and Inuit) relative to a non-Aboriginal cohort.

Methods: We linked eight years of administrative health data from Alberta and calculated age- and sex-standardized ED visit rates in cohorts of Aboriginal and non-Aboriginal individuals diagnosed with COPD. Rate ratios (RR) with 95\% confidence intervals (Cls) were calculated in a Poisson regression model that adjusted for important sociodemographic factors and comorbidities. Differences in ED length of stay (LOS) and disposition status were also evaluated.

Results: A total of 2,274 Aboriginal people and 1,611 non-Aboriginals were newly diagnosed with COPD during the study period. After adjusting for important sociodemographic and clinical factors, the rate of all-cause ED visits in all Aboriginal people ( $R R=1.72,95 \% \mathrm{Cl}: 1.67,1.77)$, particularly among Registered First Nations people (RR = 2.02; 95\% Cl: 1.97, 2.08) and Inuit ( $\mathrm{RR}=1.28 ; 95 \% \mathrm{Cl}: 1.22$, 1.35), were significantly higher than that in non-Aboriginals, while ED visit rates were significantly lower in the Métis ( $R R=0.94 ; 95 \% \mathrm{Cl}: 0.90,0.98)$. The ED LOS in all Aboriginal groups were significantly lower than that of the nonAboriginal group.

Conclusions: Aboriginal people with COPD use almost twice the amount of ED services compared to their non-Aboriginal counterparts. There are also important variations in patterns of ED services use among different Aboriginal groups with COPD in Alberta.

\section{RÉSUMÉ}

Objectif: Il s'agit d'une étude rétrospective de cohorte, visant à comparer les taux de consultation au services des urgences
(SU) après la pose d'un diagnostic de bronchopneumopathie chronique obstructive (BPCO) dans les trois groupes d'Autochtones au Canada (Indiens inscrits, Métis et Inuits) avec celui dans une cohorte de non-Autochtones.

Méthode: Ont été liées des données administratives sur la santé provenant de l'Alberta et couvrant une période de huit ans, puis calculés les taux de consultation au SU, normalisés selon l'âge et le sexe dans des cohortes d'Autochtones et de non-Autochtones chez qui un diagnostic de BPCO avait été posé. Les auteurs ont ensuite calculé les ratios de taux (RT) selon des intervalles de confiance (IC) à $95 \%$ à l'aide du modèle de régression de Poisson dans lequel ont été pris en considération des facteurs sociodémographiques importants et des maladies concomitantes. La durée du séjour au SU et les suites à donner ont aussi été évaluées.

Résultats: Un diagnostic de BPCO a été posé chez 2274 Autochtones et 1611 non-Autochtones durant la période à I'étude. Après rajustement des données pour tenir compte de facteurs sociodémographiques importants et de facteurs cliniques, le taux de consultations au SU, toutes causes confondues, dans tous les groupes d'Autochtones (RT = 1,72; IC à $95 \%: 1,67-1,77)$, en particulier parmi les Indiens inscrits $(R T=2,02 ; \mathrm{IC}$ à $95 \%: 1,97-2,08)$ et les Inuits $(\mathrm{RT}=1,28$; IC à $95 \%: 1,22-1,35)$, était significativement plus élevé que chez les non-Autochtones; par contre celui chez les Métis était sensiblement plus bas ( $R T=0,94$; IC à $95 \%: 0,90-0,98$ ). Enfin, la durée du séjour au SU dans tous les groupes d'Autochtones était passablement plus faible que celle enregistrée dans le groupe de non-Autochtones.

Conclusions: Les Autochtones atteints de BPCO utilisent presque deux fois plus les SU que les non-Autochtones. II existe également des différences importantes dans I'utilisation des SU entre les groupes d'Autochtones souffrant d'une BPCO en Alberta.

Keywords: COPD, Emergency Visits, Aboriginal people

From the *School of Public Health University of Alberta, Edmonton, AB †Alberta Health Services, Edmonton, $A B \neq$ Department of Emergency Medicine and the §Division of Pulmonary Medicine, Faculty of Medicine \& Dentistry, University of Alberta, Edmonton, AB; and the $\llbracket$ Faculty of Health Sciences, Simon Fraser University, Vancouver, BC.

Correspondence to: Maria B. Ospina, Respiratory Health Strategic Clinical Network, Alberta Health Services, 3-105D Clinical Sciences Building; 11350-83 Ave. Edmonton, Alberta; T6G 2G3; Email: mospina@ualberta.ca 


\section{INTRODUCTION}

Chronic obstructive pulmonary disease (COPD) is characterized by chronic, persistent, not fully reversible airway obstruction, systemic manifestations, and increasing frequency and severity of exacerbations that frequently result in visits to the emergency department (ED). ${ }^{1}$ The burden of COPD-related care in the ED is significant. ${ }^{2,3}$ Approximately $17 \%$ of COPD patients in North America and Europe report having at least one ED visit per year due to symptom exacerbations. ${ }^{4}$ About $1.4 \%$ of all ED visits in Canada are attributed to COPD. ${ }^{5}$ The rates of COPD-related ED visits in Alberta in individuals older than 55 years of age ranged from 25.6 per 1,000 population in 1999 to 25.1 per 1,000 population in 2005 , with an average of 2.2 visits per patient per year. ${ }^{6}$ The proportion of ED visits resulting in admission is often high, since the airway obstruction associated with exacerbations is slow to resolve. ${ }^{6}$

Aboriginal peoples in Canada (First Nations, Métis and Inuit) have a higher prevalence and incidence of COPD compared to non-Aboriginals. ${ }^{7,8}$ There remain important gaps in our knowledge about the burden of COPD in Aboriginal people relative to their nonAboriginal counterparts, ${ }^{9}$ and there is limited evidence about the patterns of ED use following a diagnosis of COPD in these populations. Analyses of administrative health data in Alberta have found that First Nations people are twice as likely to have an ED visit for COPD than non-Aboriginals. ${ }^{6,10}$ These studies, however, combined both asthma and COPD-related visits, spanned relatively short periods of follow-up, or failed to include other Aboriginal groups in the analyses.

The purpose of our study was to compare the rates of $\mathrm{ED}$ visits after a diagnosis of COPD in all three Aboriginal groups (Registered First Nations, Métis and Inuit) and a non-Aboriginal cohort with COPD, and to explore characteristics of these ED visits.

\section{METHODS}

\section{Study design and data sources}

This was a retrospective cohort study based on linkage of administrative health data in Alberta (Canada). Alberta has just over four million residents, of which $6.2 \%$ report Aboriginal ancestry (52\% First Nations people, $45 \%$ Métis and less than $1 \%$ Inuit). ${ }^{11}$ Universal health coverage under the Alberta Health Care
Insurance Plan (AHCIP) is provided to virtually all Albertans for all medically necessary physician and hospital services in the province. The federal government pays health premiums of Registered First Nations and Inuit, whereas the Métis receive health coverage from the provincial government, similar to the nonAboriginal population in Alberta.

We used de-identified, individual-level, longitudinal data from administrative databases in Alberta for fiscal years 2002 to 2009 (April 1st of a given year to March 31 st of the subsequent year) that were linked across datasets based on an encrypted unique personal health number. The AHCIP registry contains demographic information; the Alberta Ambulatory Care Classification System (ACCS) collects information on all ED visits in Alberta using the International Classification of Diseases, 10th Revision, enhanced Canadian version (ICD-10-CA $)^{12}$ for diagnosis coding. Claims for services provided by fee-for-service physicians and physicians paid under alternate payment plans with diagnostic fee codes based on the International Classification of Diseases, 9th Revision (ICD-9) ${ }^{13}$ are recorded in the Alberta Physician Claims Assessment System. Alberta Vital Statistics contains verified certificate data of all deaths in the province. The Métis Nation of Alberta (MNA) registry contains citizenship information for members of the Métis Nation of Alberta who identify themselves as Métis.

\section{Study population}

The Aboriginal cohort consisted of Registered First Nations people, Inuit (both identified in the AHCIP based on an alternate premium arrangement), and Métis included in the MNA registry. Non-Aboriginals were classified as individuals in the AHCIP without an alternate premium arrangement field nor included in the MNA registry. First Nations people without registration status $^{14}$ and Métis not registered in the MNA were considered non-Aboriginals because there is no reliable method to identify them within the general population. ${ }^{15}$ Individuals included in the cohorts were required to have had constant registration in the AHCIP between fiscal years 2002 to 2009 , and be at least 35 of age at the beginning of each year. All Métis and Inuit in the AHCIP/population registry who met the eligibility criteria were included in the Aboriginal cohort, while random samples of eligible Registered First Nations people and non-Aboriginals were selected from the 


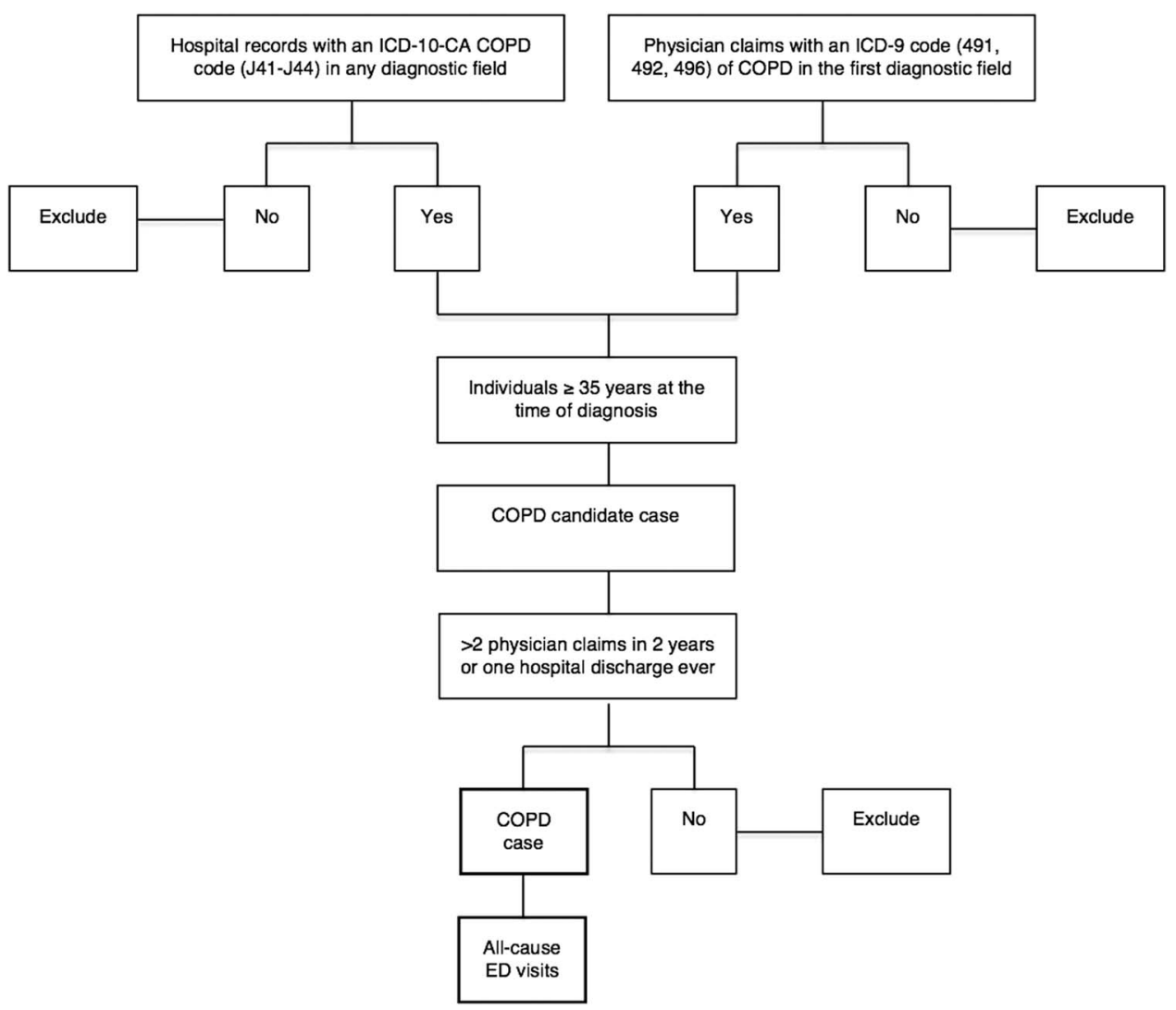

Figure 1. Algorithm for COPD case identification in administrative databases.

AHCIP/population registry for a ratio of five Registered First Nations people and five non-Aboriginals per Métis person included.

We identified individuals in the cohorts who were newly diagnosed with COPD during the study period according to the following validated case definition: individuals aged 35 years and older at the time of diagnosis who had at least two physician claims with an ICD-9 code of COPD $(491,492,496)$ in the first diagnostic field in a two-year period, or one recording of an ICD-10-CA code (J41-J44) of COPD in any diagnostic field in the hospital file ever, whichever came first (Figure 1). ${ }^{16,17}$ This COPD algorithm has been previously validated with sensitivity of $68.4 \%$, specificity of $93.5 \%$, positive predictive value of $79.2 \%$, and negative predictive value of $89.1 \%{ }^{16}$

\section{Statistical analysis}

The primary outcome was the rate of all-cause ED visits. Only ED visits that occurred after the date of
COPD diagnosis were included in the analysis. Secondary outcomes were ED length of stay (LOS) and disposition status at the end of ED visit.

The following sociodemographic information was extracted from the AHCIP registry: sex (male or female), age at the time of COPD diagnosis (35 to 64 years, 65 years and older), and area of residence (urban, rural, and remote) at COPD diagnosis. As there is no direct measure of socioeconomic status (SES) available from administrative health databases, the need for, and receipt of health care subsidies (full, partial, none) is considered a proxy measure of SES within the Canadian health care system. ${ }^{18}$

Comorbidities were defined as the presence of one or more distinct common diseases in addition to COPD. ${ }^{19,20} \mathrm{We}$ used validated case algorithms to identify the following comorbidities that have been associated with an increase in health services use in COPD patients: hypertension, ${ }^{21,22}$ diabetes mellitus, ${ }^{23}$ ischemic heart disease, ${ }^{24}$ asthma, ${ }^{25}$ and osteoporosis. ${ }^{26}$

Annual rates of all-cause ED visits were calculated from fiscal years 2002 to 2009 . The numerator was the 
number of episodes of ED care per person per year and the denominator was the person-time of observation, defined as the sum of the time that each person with COPD remained under observation from beginning of the fiscal year (if the person was diagnosed in previous years) or COPD diagnosis date (if the person was diagnosed during the year) until death, or end of fiscal year, whichever came first.

Incidence density rates of all-cause ED visits were calculated for the entire study period, with the numerator being the total number of episodes of ED care that occurred between 2002/2003 and 2009/2010 divided by total person-time of observation (the sum of the time that each person remained under observation from COPD diagnosis date until death, or end of study). All rates were expressed as number of events per 1,000 person-years with Poisson 95\% confidence intervals (CIs) calculated around the estimates. ${ }^{27}$

Characteristics of ED visits were captured by median length of stay and proportions of disposition status at the end of the ED episode of care (discharged, admitted, death, left before completion of ED care). We calculated unadjusted rate ratios (RRs) with $95 \%$ CI for all-cause ED visits for the entire study period. Poisson regression models were used to adjust the RRs for other covariates at baseline with person-time considered as the offset in the model ${ }^{27}$ and the non-Aboriginal cohort as the reference category. Covariates fit in the Poisson model were sex, age group, SES proxy, area of residence and the presence of important comorbidities (e.g., hypertension, ischemic heart disease, asthma, diabetes mellitus and osteoporosis).

Two-sided $p$ values less than 0.05 represented statistical significance for all analyses. Statistical analyses were performed using Predictive Analysis Software Statistics for Mac $^{\circledR}\left(\right.$ PASW $^{\circledR}$ version 18.0, IBM SPSS, Somers, NY).

The University of Alberta Health Research Ethics Board granted ethics approval to conduct this study. Individual patient consent was not required and patient records and information were anonymized and de-identified prior to analysis.

\section{RESULTS}

A total of 2,274 Aboriginal people (1,764 Registered First Nations, 329 Métis, and 181 Inuit) and 1,611 nonAboriginals were newly diagnosed with COPD during the study period (Table 1).

Overall, annual rates of all-cause ED visits in the Aboriginal groups diagnosed with COPD were consistently higher than those in their non-Aboriginal counterparts (Figure 2). For the entire study period,

\begin{tabular}{|c|c|c|c|c|c|}
\hline & $\begin{array}{l}\text { All Aboriginal } \\
\text { people }\end{array}$ & $\begin{array}{l}\text { Registered First } \\
\text { Nations }\end{array}$ & Métis & Inuit & $\begin{array}{c}\text { Non- } \\
\text { Aboriginals }\end{array}$ \\
\hline Newly diagnosed with COPD & 2,274 & 1,764 & 329 & 181 & 1,611 \\
\hline Person-time (years) & $8,511.0$ & $6,461.3$ & $1,319.1$ & 730.5 & $5,719.8$ \\
\hline Male (\%) & $46 \%$ & 44.0 & 49.2 & 59.1 & $54.7 \%$ \\
\hline \multicolumn{6}{|l|}{ Age groups (\%) } \\
\hline $35-64$ years & 65.4 & 68.7 & 61.4 & 41.4 & 34.8 \\
\hline$\geq 65$ years & 34.6 & 31.3 & 38.6 & 58.6 & 65.2 \\
\hline \multicolumn{6}{|l|}{ Area of residence (\%) } \\
\hline Urban & 41.3 & 37.9 & 52.9 & 53.0 & 69.2 \\
\hline Rural & 39.1 & 40.8 & 35.9 & 28.7 & 27.8 \\
\hline Remote & 19.6 & 21.3 & 11.2 & 18.2 & 3.0 \\
\hline \multicolumn{6}{|l|}{ Subsidy level (\%) } \\
\hline Full/Partial & 39.2 & 33.6 & 56.2 & 62.4 & 66.7 \\
\hline None & 60.8 & 66.4 & 43.8 & 37.6 & 33.3 \\
\hline \multicolumn{6}{|l|}{ Comorbidities (\%) } \\
\hline Hypertension & 17.2 & 17.0 & 16.7 & 19.9 & 18.9 \\
\hline $\mathrm{IHD}$ & 11.0 & 10.0 & 14.3 & 14.9 & 12.1 \\
\hline Asthma & 10.4 & 11.0 & 8.8 & 7.7 & 9.1 \\
\hline DM & 8.5 & 8.7 & 7.3 & 8.8 & 7.7 \\
\hline Osteoporosis & 3.3 & 2.9 & 4.0 & 5.0 & 5.7 \\
\hline
\end{tabular}




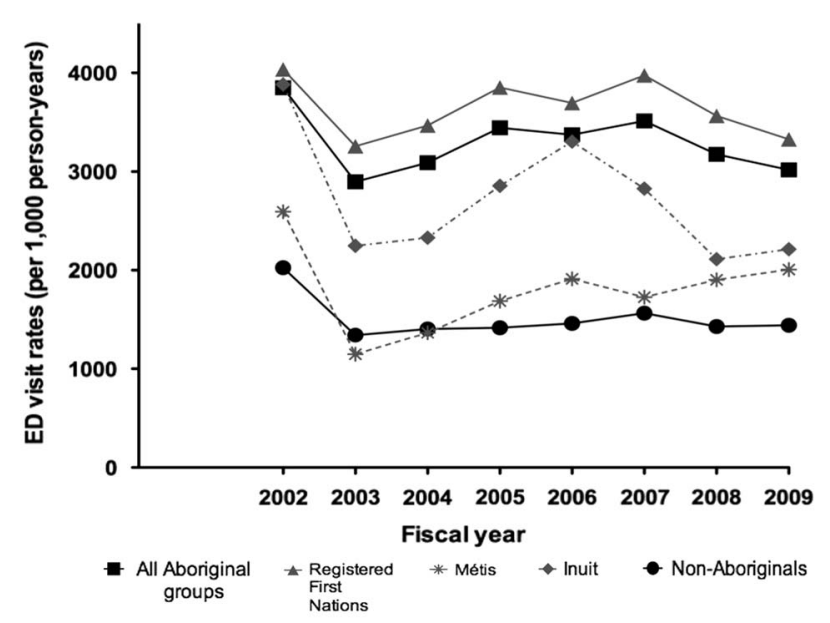

Figure 2. Annual rates of all-cause ED visits in Aboriginal and non-Aboriginal cohorts diagnosed with COPD, 2002 to 2009.

all-cause ED visit rates in all Aboriginal COPD groups combined (3,242.7 ED visits per 1,000 person-years; 95\% CI: 3,205.4, 3,281.3) were higher than those of non-Aboriginals $(1,460.1$ ED visits per 1,000 person-years; 95\% CI: 1,429.2, 1,492.3). Registered First Nations people with COPD had the highest rates of $\mathrm{ED}$ visits $(3,612.5 \mathrm{ED}$ visits per 1,000 person-years; 95\% CI: 3,566.1, 3,659), followed by the Inuit $(2,574.4$ ED visits per 1,000 person-years; 95\% CI: 2,460.1, 2,694.0) and the Métis (1,801.2 ED visits per 1,000 person-years; 95\% CI: 1,730.1, 1,875.4).

Figure 3 shows rate ratios of all-cause ED visits in Aboriginal people with COPD. After adjusting for important socioeconomic factors and the presence of comorbidities, we found that all-cause ED visit rates given COPD were significantly higher in the group of all Aboriginal peoples combined than those in the nonAboriginal group $\left(\mathrm{RR}_{\mathrm{adj}}=1.72,95 \% \mathrm{CI}: 1.67,1.77\right)$. Multivariate analyses for Aboriginal subtypes found that, compared to the non-Aboriginal group, all-cause ED visit rates in Registered First Nations people $\left(\mathrm{RR}_{\mathrm{adj}}=2.02 ; 95 \% \mathrm{CI}: 1.97,2.08\right)$ and the Inuit $\left(\mathrm{RR}_{\mathrm{adj}}=1.28 ; 95 \% \mathrm{CI}: 1.22,1.35\right)$ were significantly higher, but rates amongst the Métis were significantly lower $\left(\mathrm{RR}_{\mathrm{adj}}=0.94 ; 95 \% \mathrm{CI}: 0.90,0.98\right)$.

The median ED LOS in Registered First Nations people (1 hour; IQR: 0, 4), Métis (1 hour; IQR: 0, 3) and Inuit (1 hour; IQR: 0,3$)$ were shorter than that of the non- Aboriginal group (2 hours; IQR: 1, 5). As shown in Table 2, compared to non-Aboriginals, there was a higher proportion of ED visits in Aboriginal people ending in discharge from the ED $(77.7 \%$ versus $71.3 \%)$ or leaving before completion of care $(5.0 \%$ versus $2.4 \%$ ). In contrast, a higher proportion of nonAboriginal individuals with COPD were admitted to hospital $(17.2 \%$ versus $26 \%)$.

\section{DISCUSSION}

This is the first study in Canada to provide a comprehensive longitudinal assessment of the pattern of ED services following a diagnosis of COPD in the three Aboriginal groups of Canada compared to a nonAboriginal reference group. Using a validated algorithm for case identification of COPD and after adjusting for important sociodemographic factors, we found that Aboriginal people with COPD as a whole had significantly higher rates of all-cause ED visits compared to non-Aboriginals with COPD. Aboriginal subgroups showed distinct patterns of ED visits following a diagnosis of COPD. Rates of all-cause ED visits were significantly higher in Registered First Nations people and Inuit, but lower in the Métis group compared to their non-Aboriginal counterparts. Despite having higher ED visit rates, Aboriginal people with COPD were found to spend approximately 1 hour less time in the ED than non-Aboriginals.

Our results are similar to those of studies comparing ED visit rates for COPD between Registered First Nations people and non-Aboriginal groups in Alberta: Registered First Nations people were more likely to visit the ED for COPD exacerbations. ${ }^{6,10}$ The results, however, differ from those of Klein-Geltink and colleagues ${ }^{28}$ who reported that the mean number of overall ED visits among those diagnosed with COPD were 1.3 times higher among Métis compared to the general population in Ontario, while there were no differences between the two groups in the proportion of COPDspecific ED visits. ${ }^{28}$ Discrepancies in study results may be related to differences in the analytical approach and the observation period of the studies. There are no published data to compare the results of ED visits rates in Inuit with COPD.

Differences in ED visit rates in Aboriginal groups with COPD relative to their non-Aboriginal counterparts in our study may arise from a variety of factors that are determinants of quality of care in COPD. It is possible that Aboriginal people with COPD use more ED services, either because they have higher disease severity $^{29}$ that leads to frequent or more severe 
ED visits $R R(95 \% \mathrm{Cl})$

All Aboriginal groups

Unadjusted $\quad 1.95(1.90,2.00)$

Adjusted $^{\star} \quad 1.72(1.67,1.77)$

Registered First Nations

Unadjusted $\quad 2.21(2.16,2.27)$

Adjusted $^{\star} \quad 2.02(1.97,2.08)$

Métis

Unadjusted $\quad 1.07(1.02,1.12)$

Adjusted $^{\star} \quad 0.94(0.90,0.98)$

Inuit

Unadjusted $1.36(1.29,1.43)$

Adjusted * $1.28(1.22,1.35)$

0

Lower rate in Aboriginal group

HAH

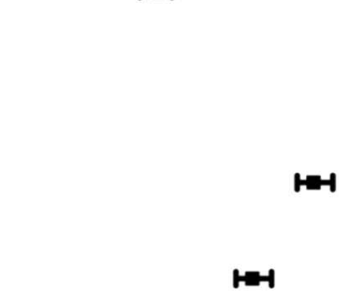

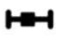

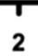

Higher rate in Aboriginal group

$\mathrm{Cl}=$ confidence interval; $\mathrm{COPD}=$ chronic obstructive pulmonary disease $; \mathrm{ED}=$ emergency department; $\mathrm{RR}=$ rate ratio

* Poisson regression model adjusted for sex (male, female), age group (35-64 years, 65 years and over), socioeconomic status proxy (full/partial subsidy, no subsidy), area of residence (urban rural, remote), and presence of comorbidities (hypertension, ischemic heart disease, asthma, diabetes mellitus, osteoporosis)

Figure 3. Rate ratios of all-cause ED visits in Aboriginal people with COPD.

\begin{tabular}{|c|c|c|c|c|c|}
\hline & All Aboriginal people & Registered First Nations & Métis & Inuit & Non-Aboriginals \\
\hline $\mathrm{N}$ visits & 26,010 & 22,027 & 2,231 & 1,752 & 8,028 \\
\hline ED LOS (hours) (median, IQR) & $2.8(2.7,2.9)$ & $2.9(2.8,3.0)$ & $2.4(2.2,2.5)$ & $2.2(2.0,2.3)$ & $3.7(3.4,3.6)$ \\
\hline $\mathrm{N}$ all-cause ED visits & 27,599 & 23,342 & 2,376 & 1,881 & 8,352 \\
\hline \multicolumn{6}{|l|}{ Disposition status (\%) } \\
\hline Discharged & 77.7 & 77.0 & 80.9 & 82.5 & 71.3 \\
\hline Admitted & 17.2 & 17.6 & 15.7 & 14.2 & 26.0 \\
\hline Death & 0.1 & 0.2 & 0.1 & 0.0 & 0.3 \\
\hline Left before completion of care (\%) & 5.0 & 5.3 & 3.3 & 3.3 & 2.4 \\
\hline
\end{tabular}


exacerbations, or due to poorer chronic management for COPD and/or comorbidities that lead to treatment failure and disease relapse that requires frequent emergency care. ${ }^{30}$ It is also possible that certain Aboriginal groups use the ED as a "safety net of health care" rather than primary care providers, particularly if they belong to socially and economically disadvantaged communities. $^{31,32}$ Data from the 2006 Aboriginal Peoples Survey (APS) showed that the proportion of Aboriginal people who have a regular physician (81\%) is lower than the national average in Canada $(85 \%) .{ }^{33,34}$ In particular, First Nations people living in rural and isolated communities are more likely to report difficulties accessing health providers, including regular physicians and specialists. ${ }^{35}$ Similarly, the survey found that Métis and Inuit adults had poorer access to a regular physician compared to the general population. ${ }^{33,34}$

Approximately $10 \%$ of individuals are diagnosed with COPD for the first time in the $\mathrm{ED},{ }^{36}$ suggesting that in many instances, the condition remains undetected at the primary care level and many individuals with COPD go to the ED rather than to physician offices for symptoms or conditions that could be otherwise managed out of the ED. The existence of barriers affecting the access to diagnosis and treatment for COPD, the shortage of regular family physicians, and in a broader perspective, an inadequate organization of the primary care services to address the needs of Aboriginal populations with COPD could account for the differences in the use of ED services between Aboriginal and non-Aboriginal cohorts with COPD.

Other potentially explanatory factors underlying the observed patterns of ED attendance in Aboriginal people with COPD include cultural differences, perception of health services and providers, and health literacy issues. Evidence from qualitative research has established that, as a result of histories of abuse and discrimination and prior negative experiences with the health care system, Aboriginal people may not seek medical care at the frequency expected of Canadians in the general population. ${ }^{37,38}$

We found that the three Aboriginal groups with COPD had shorter ED LOS than their non-Aboriginal counterparts, with differences in disposition status among groups. These findings could arise from either positive or negative factors: a shorter LOS may indicate that Aboriginal people are treated faster in the ED; alternatively, it may indicate that their condition could have been treated in outpatient settings and that the ED visit could have been avoided if better access to physician ambulatory services were available. Our analysis of ED disposition status revealed that more Aboriginal people with COPD left the ED before completion of care compared to their non-Aboriginal counterparts (5.0\% versus $2.4 \%$ ), and this could explain the shorter ED LOS. Post-hoc analyses showed that, compared to non-Aboriginal people with COPD, more Aboriginal people with COPD concluded their ED visits because they left against medical advice (LAMA) (3.9\% versus $2.2 \%)$, or left without being seen (LWBS) $(0.8 \%$ versus $0.2 \%$ ). Further studies are required to explore the outcomes of ED visits and other characteristics of Aboriginal people and non-Aboriginals who are frequent users of ED services.

There are a number of limitations in this study inherent to the quality and comprehensiveness of administrative data. First, the process of diagnosing COPD is complex and imperfect. While the diagnosis of COPD was not clinically confirmed, the algorithm we used for case identification has been found to be both valid and accurate. To conduct a similar sized prospective clinical study would require an enormous funding commitment and many years of research compared to the efficiency of using administrative data.

Superficial clinical details in administrative databases precluded the acquisition of information on key sociodemographic and clinically important confounding variables to adjust the baseline risk for COPD in multivariate analyses. While the multivariate analyses adjusted for important covariates at baseline (e.g., sex, age, area of residence, SES, comorbidities), key factors such as disease severity, smoking history, and smoking status are not routinely captured in the administrative health datasets used for this study, and therefore could not be included in the analyses. Future studies using multi-level approaches would be needed to explore these differences further and to assess the impact of disease severity, smoking, ED geographic location, ED case-mix, and social determinants as potential barriers to health services access. ${ }^{39}$

Efforts to mitigate the misclassification bias affecting exposure (i.e., being Aboriginal) may not have been completely successful in our study. Limitations encountered in similar studies regarding the proper identification of non-Registered Aboriginal peoples persisted, although to a lesser degree. For example, an individual who was classified in the non-Aboriginal group may have been in fact, a non-Registered First 
Nations person or a Métis without citizenship registration under the MNA. It is also possible that First Nations peoples with Registered status and Métis individuals registered with the MNA may be different (in demographic or clinical terms) than non-Registered First Nations peoples and non-registered Métis in the province. In 2011, First Nations peoples without registration status represented $25.1 \%$ of the total number of First Nations peoples in Canada. ${ }^{11}$ Similarly, it is estimated that as few as $30 \%$ of Métis in the province are members of the MNA, and therefore a substantial number of non-MNA Métis were not included in our study or were misclassified in the non-Aboriginal group. Misclassification bias in the study may have led to undercounting of approximately one-third of Aboriginal people in the province. If anything, the magnitude of the differences in epidemiological indicators of COPD between Aboriginal peoples and the non-Aboriginal populations has likely been underestimated as a result of misclassification of non-Registered First Nations people and non-MNA Métis, for had we had the correct classification of all Aboriginal people, such differences would have been more precise.

As we used a cohort design with linkage across provincial administrative health databases involving a large number of people and continuity of data over a relatively long follow-up period, we feel is is likely that our results can be generalized to all Aboriginal people in Alberta and allow inferences that can be applied to Aboriginal populations in other Canadian provinces.

\section{CONCLUSION}

Aboriginal people with COPD, as a whole, use almost twice the amount of ED services compared to nonAboriginal people with COPD. The patterns of ED visits with COPD, however, differ among the three Aboriginal groups, with First Registered Nations people consistently showing higher rates in all indicators evaluated. Further research should explore whether barriers to accessing family physicians and other primary care services contribute to these differences.

Competing Interests: Dr. Ospina received financial support through a PhD Studentship Award from the Canadian Thoracic Society and the Canadian Lung Association. Dr. Stickland is supported by a New Investigator Award from the Heart and Stroke Foundation of Canada. Dr. Rowe is supported by CIHR as a Tier I Canada Research Chair in Evidence-based Emergency Medicine through the Government of Canada (Ottawa, ON). This study is based on data provided by Alberta Health. The interpretation and conclusions contained herein are those of the researchers and do not necessarily represents the views of the Government of Alberta or Alberta Health. The authors have no other competing interests to declare.

\section{REFERENCES}

1. Global Strategy for the Diagnosis, Management and Prevention of COPD. Global Initiative for Chronic Obstructive Lung Disease (GOLD) 2013. Available at: www.goldcopd. org/ (accessed February 3, 2013).

2. Yeatts KB, Lippmann SJ, Waller AE, et al. Population-based burden of COPD-related visits in the emergency department (ED): return ED visits, hospital admissions, and comorbidity risks. Chest 2013;144(3):784-93, doi: 10.1378/ chest.12-1899.

3. FitzGerald JM, Haddon JM, Bradly-Kennedy C, et al. Resource use study in COPD (RUSIC): a prospective study to quantify the effects of COPD exacerbations on health care resource use among COPD patients. Can Respir 7 2007;14(3):145-52.

4. Chapman KR, Bourbeau J, Rance L. The burden of COPD in Canada: results from the Confronting COPD survey. Respir Med 2003;97(Suppl C):S23-31.

5. Rowe BH, Cydulka RK, Tsai CL, et al. Comparison of Canadian versus United States emergency department visits for chronic obstructive pulmonary disease exacerbation. Can Respir 7 2008;15(6):295-301.

6. Rosychuk RJ, Voaklander DC, Senthilselvan A, et al. Presentations to emergency departments for chronic obstructive pulmonary disease in Alberta: a populationbased study. CFEM 2010;12(6):500-8.

7. Ospina MB, Voaklander D, Senthilselvan A, et al. Incidence and prevalence of chronic obstructive pulmonary disease among Aboriginal peoples in Alberta, Canada. PLoS One 2015;10(4):e0123204.

8. Martens P, Bartlett J, Burland E, et al. Profile of Métis health status and healthcare utilization in Manitoba: a population-based study. Winnipeg: Manitoba Centre for Health Policy in Collaboration with the Manitoba Métis Federation; 2010.

9. Ospina MB, Voaklander DC, Stickland MK, et al. Prevalence of asthma and chronic obstructive pulmonary disease in Aboriginal and non-Aboriginal populations: a systematic review and meta-analysis of epidemiological studies. Can Respir 7 2012;19(6):355-60.

10. Sin DD, Wells H, Svenson LW, et al. Asthma and COPD among aboriginals in Alberta, Canada. Chest 2002; 121(6):1841-6.

11. Statistics Canada. Aboriginal Peoples in Canada: First Nations People, Métis and Inuit. National Household Survey Catalogue No. 99-011-X2011001. Ottawa: Statistics Canada; 2013.

12. Canadian Institute for Health Information. The Canadian enhancement of ICD-10. Ottawa: Canadian Institute for Health Information; 2001.

13. Government of Canada. Indian Act; 1996. Cat. No. YX76-IS/ 1996. 
14. World Health Organization. International Statistical Classification of Diseases, Injuries, and Causes of Death, 9th Revision. Geneva: World Health Organization; 1979.

15. Anderson M, Smylie J, Anderson I, et al. First Nations, Inuit and Métis bealth indicators in Canada. Melbourne: The University of Melbourne; 2006.

16. Gershon AS, Wang C, Guan J, et al. Identifying individuals with physician diagnosed COPD in health administrative databases. COPD 2009;6(5):388-94.

17. Evans J, McRae L, on behalf of the Canadian Chronic Disease Surveillance System Chronic Respiratory Disease Working Group. Recommendations to the Canadian Chronic Disease Surveillance System - Scientific Working Group. Ottawa: Public Health Agency of Canada; 2010.

18. Wang F, Gabos S, Mackenzie A. The socioeconomic status marker from administrative data: is it accurate? Paper presented at the IEA: XVI World Congress of Epidemiology, Montreal, August 18-22, 2002.

19. Sin DD, Anthonisen NR, Soriano JB, et al. Mortality in COPD: Role of comorbidities. Eur Respir 7 2006;28(6):1245-57.

20. Chatila WM, Thomashow BM, Minai OA, et al. Comorbidities in chronic obstructive pulmonary disease. Proc Am Thorac Soc 2008;5(4):549-55.

21. Public Health Agency of Canada. Report from the Canadian Chronic Disease Surveillance System: Hypertension in Canada, 2010. Ottawa: Minister of Health; 2010.

22. Tu K, Campbell NR, Chen ZL, et al. Accuracy of administrative databases in identifying patients with hypertension. Open Med 2007;1(1):e18-26.

23. Public Health Agency of Canada National Diabetes Surveillance System. Report from the national diabetes surveillance system: Diabetes in Canada, 2009. Ottawa: Minister of Health; 2009.

24. Tu K, Mitiku T, Lee DS, et al. Validation of physician billing and hospitalization data to identify patients with ischemic heart disease using data from the Electronic Medical Record Administrative data Linked Database (EMRALD). Can 7 Cardiol 2010;26(7):e225-8.

25. Huzel L, Roos LL, Anthonisen NR, et al. Diagnosing asthma: the fit between survey and administrative database. Can Respir 7 2002;9(6):407-12.

26. Leslie WD, Lix LM, Yogendran MS. Validation of a case definition for osteoporosis disease surveillance. Osteoporosis Int 2011;22(1):37-46.
27. Rosner B. Fundamentals of Biostatistics, 6th ed Belmont: Duxbury Press; 2005.

28. Klein-Geltink J, Khan S, Cascagnette P, et al. Respiratory disease in the Métis Nation of Ontario. Toronto: Institute for Clinical Evaluative Sciences; 2012.

29. Pines JM, Asplin BR, Kaji AH, et al. Frequent users of emergency department services: gaps in knowledge and a proposed research agenda. Acad Emerg Med 2011;18(6): e64-9.

30. Restrepo RD, Alvarez MT, Wittnebel LD, et al. Medication adherence issues in patients treated for COPD. Int 7 Chron Obstruct Pulmon Dis 2008;3(3):371-84.

31. Blanchard JC, Haywood YC, Scott C. Racial and ethnic disparities in health: an emergency medicine perspective. Acad Emerg Med 2003;10(11):1289-93.

32. Browne AJ, Smye VL, Rodney $\mathrm{P}$, et al. Access to primary care from the perspective of Aboriginal patients at an urban emergency department. Qual Health Res 2011; 21(3):333-48.

33. Tait H. Aboriginal Peoples Survey, 2006: Inuit bealth and social conditions Catalogue no. 89-637-X - No. 001. Ottawa: Statistics Canada; 2008.

34. Janz T, Seto J, Turner A. Aboriginal Peoples Survey, 2006: an overview of the bealth of the Métis population Catalogue no. 89-637-X-No. 004. Ottawa: Statistics Canada; 2009.

35. Wilson K, Rosenberg MW. Exploring the determinants of health for First Nations peoples in Canada: can existing frameworks accommodate traditional activities? Soc Sci Med 2002;55(11):2017-31.

36. Aaron S, Vandemheen KL, Hebert P, et al. Outpatient oral prednisolone after emergency treatment of chronic obstructive pulmonary disease. $N$ Engl 7 Med 2003; 348(26):2618-24.

37. Adelson N. The embodiment of inequity: health disparities in aboriginal Canada. Can 7 Public Health 2005;96(Suppl 2): S45-61.

38. Richmond CA, Ross NA. The determinants of First Nation and Inuit health: a critical population health approach. Health Place 2009;15(2):403-11.

39. Marrone S. Understanding barriers to health care: a review of disparities in health care services among indigenous populations. Int 7 Circumpolar Health 2007;66(3): 188-98. 